\title{
Pengaruh Media Crossword Puzzle dalam Meningkatkan Maharah Qira'ah Siswa SMA Islam Sabilillah Malang Boarding School
}

\author{
Apri Wardana Ritonga \\ Tazkia International Islamic Boarding School (IIBS) Malang \\ wardanaapri90@gmail.com
}

\author{
Article History: \\ Received: \\ 30 November 2020 \\ Revised: \\ 14 Desember 2020 \\ Accepted: \\ 30 Desember 2020
}

\section{Keywords:}

Learning Media, Crossword

Puzzle, Reading Skill

\begin{abstract}
:
Maharah qira'ah is one of the Arabic language skills that students must have. Teaching maharah qira'ah should be done in a variety of interesting media so that learning becomes fun and enjoyable. Crossword puzzles are an option that can be used as a medium in teaching maharah qira'ah to students. This study aims to determine the effect of the crossword puzzle media in learning maharah qira'ah. The experimental method with the form of pre-experimental research design is the method used in this study. The population that became the object of the study was 125 students of class XII SMA Islam Sabilillah Malang Boarding School consisting of 5 classes, two female classes and three male classes. Based on the results of data analysis, the pre-test mean score was 79.83 (80), and the post-test average score was 85.43 (85). With the results of the analysis of $t_{\text {count }} 91.539$ and $t_{\text {table }} 2.001$, it means that $t_{\text {count }}>t_{\text {table. }}$ So Ho is rejected and $\mathrm{Ha}$ is accepted with a significance level of $0.2 \%$. So, it can be concluded that there is an effect of using crossword puzzle media in improving maharah qira'ah for XII grade students of SMA Islam Sabilillah Malang Boarding School.
\end{abstract}

\section{Pendahuluan}

Salah satu indikator keberhasilan inovasi pembelajaran dalam bahasa Arab adalah penggunaan media dalam proses pembelajaran dengan efektif. Inovasi pembelajaran bahasa Arab ini perlu dilakukan untuk meningkatkan mutu pembelajaran di bidang bahasa Arab. Hal ini juga dilakukan untuk meningkatkan keinginan dan cinta peserta didik untuk belajar bahasa Arab.

Dewasa ini, paradigma peserta didik terhadap bahasa Arab sangat memprihatinkan bila dibandingkan dengan minat mereka terhadap bahasa asing lainnya. Bahkan tidak jarang kita mendengar siswa yang mengeluhkan sulitnya belajar bahasa Arab. Mengapa hal itu terjadi, di antara jawabannya adalah pembelajaran bahasa Arab yang diaplikasikan di sekolah cukup monoton. Sehingga dirasa perlu untuk melakukan inovasi terhadap pembelajaran bahasa Arab di sekolah, agar tidak tertinggal dengan pelajaran bahasa asing lainnya di era globalisasi yang semakin berkembang ini.

Perkembangan teknologi saat ini melahirkan model baru dalam pembelajaran yang berlangsung di dalam kelas. Hal ini memberi dampak positif terhadap pendidikan karena siswa menjadi lebih aktif untuk mempelajari ragam ilmu pengetahuan melalui media yang disampaikan. 
Meskipun demikian, guru dituntut agar lebih menguasai media yang disajikan kepada siswa, agar pembelajaran bisa berjalan dengan lancar tanpa adanya hambatan saat proses pembelajaran berlangsung. Aliba'ul Husna menyebutkan bahwa salah satu penyebab tidak tercapaianya tujuan pembelajaran adalah guru yang berperan penting dalam sistem pendidikan tidak memiliki skilluntuk mengoperasikan media pembelajaran ${ }^{1}$.

Pembelajaran bahasa Arab yang diselenggarakan di lembaga pendidikan formal masih sering menggunakan metode klasik/tradisional, ceramah, bahkan tidak jarang pembalajaran hanya bergantung kepada buku paket. Fenomena seperti ini hanya akan menjadikan siswa jenuh dan bosan belajar bahasa Arab². Perlu dilakukan rekonstruksi dalam proses pembelajaran bahasa Arab untuk tercapaianya tujuan pembelajaran dengan baik. Salah satu upaya yang bisa dilakukan oleh guru ialah dengan memperbaiki media yang digunakan dalam proses pembelajaran.

Terminologi media diklasifikasikan kepada dua bagian besar, seperti yang dikemukakan oleh Abdul Wahab Rasyidi, bahwa perpaduan perangkat keras (hardware) dan perangkat lunak (software) disebut dengan media. Atau dengan istilah lain bahwa media tersebut adalah perangkat keras yang disi dengan perangkat lunak ${ }^{3}$. Dengan demikian, bisa disimpulkan bahwa alat yang digunakan untuk menyampaikan isi pesan disebut dengan media, pikiran menjadi terpanggil untuk melakukan, dapat membangkitkan semangat, attention dan keinginan seseorang sehingga mereka tertarik untuk mengikuti pembelajaran dengan baik.

Sejalan dengan pengertian media di atas, Oemar Hamalik mengatakan bahwa alat, metode, dan teknik yang digunakan seseorang untuk menjadikan komunikasi, interaksi dan hubungan antara guru dengan siswa bisa terjalin dengan baik dalam proses pembelajaran yang diselenggarakan di sekolah disebut dengan media pembelajaran ${ }^{4}$. Interaksi positif yang terjalin antara guru dan siswa akan menumbuhkan semangat belajar pada diri siswa.

Kesimpulan yang bisa diambil dari pengertian media di atas adalah media itu alat yang digunakan seseorang untuk mewujudkan tujuan tertentu. Baik orang, bahan, alat yang dengan bantuannya siswa dapat memenuhi pengetahuan, sikap dan keterampilan. Dengan kata lain, guru, buku teks dan lingkungan sekolah seluruhnya adalah bagian dari media pembelajaran ${ }^{5}$.

Media pembelajaran tidak selalu akan sesuai dengan kondisi belajar siswa. Agar terwujudnya pembelajaran yang efektif dan efisien, persiapan yang matang dan keterampilan guru pun perlu

\footnotetext{
1 Aliba`ul Chusna, "Pembelajaran Bahasa Arab Berbasis Multimedia," Cendekia: Jurnal Kependidikan Dan Kemasyarakatan 10, no. 2 (2012): 278, https://doi.org/10.21154/cendekia.v10i2.416.

2 Abdul Aziz Khoiri dan Ilham Fatkhu Romadhon, "Arabic Teacher: Pembelajaran Modern Bahasa Arab Berbasis E-Learning Bagi Non-Native Speaker,” in Prosiding Konferensi Nasional Bahasa Arab III, vol. 53, 2017, 290, https://doi.org/10.1017/CBO9781107415324.004.

3 Abdul Wahab Rosyidi, Media Pembelajaran Babasa Arab (Malang: UIN Malang Press, 2009).

${ }^{4}$ Oemar Hamalik, Media Pendidikan (Bandung: Citra Aditya, 1989).

${ }^{5}$ Amir Achsin, Media Pendidikan (Ujung Pandang: IKIP, 1986).
} 
diperhatikan. Banyak faktor yang mempengaruhi keberlangsungan pembelajaran dalam kelas, seperti halnya ungkapan Nandang Sarip Hidayat alokasi waktu yang digunakan, psikologi siswa, gaya belajar, karakteristik siswa, strategi belajar, fasilitas belajar, infrastruktur sekolah, manajemen sekolah serta prosedur penilaian juga perlu diperhatikan ${ }^{6}$.

Pembelajaran yang baik tidak terlepas dari media yang yang baik pula dan guru memiliki keterampilan untuk menggunakannya. Muhammad Ahmad Salim dalam Imam Makruf menjelaskan dalam memilih media perlu diperhatikan beberapa hal, sebagai berikut : 1) Tujuan pembelajaran harus sesuai dengan media yang digunakan. 2) Media yang digunakan adalah sesuatu yang mudah didapat dan guru terampil untuk menggunakannya. 3) Media tersebut dapat membangkitkan motivasi dan dan daya tarik siswa. 4) Media yang dipilih dapat memberikan informasi baru bagi siswa. 5) Penggunaan media harus sesuai dengan tingkat daya berpikir siswa. Dan 6) gunakanlah terlebih dahulu media tersebut sebelum digunakan dalam proses pembelajaran ${ }^{7}$. Nana Sudjana menambahkan bahwa guru harus mempertimbangkan alokasi waktu dalam menggunakan media pembelajaran dan media tersebut adalah dukungan terhadap isi materi yang diajarkan ${ }^{8}$. Namun perlu diperhatikann bahwa media yang digunakan itu juga harus sesuai dengan tingkat usia siswa yang diajarkan. Media pembelajaran untuk siswa sekolah dasar tentu berbeda dengan tingkat SMP, SMA hingga perguruan tinggi.

Salah satu permainan yang populer di kalangan remaja maupun dewasa adalah crossword puzzle. Dari namanya, crossword puzzle menjadi alternatif sederhana yang bisa digunakan untuk mengasah kemampuan berpikir dan menalar. Dalam crossword puz:le seseorang akan ditantang untuk mengisi kotak kotak kosong dengan huruf, baik kotak yang mendatar maupun menurun sehingga membentuk sebuah kata yang mengandung arti. Permainan sederhana ini sudah sangat lumrah digunakan dalam dunia pendidikan. Buktinya, banyak guru dan siswa yang menggunakan media crossword puгzle sebagai sarana belajar dalam kelas. Nia Hidayati menyebutkan bahwa penggunaan crossword puz:le sebagai media pembelajaran menjadi efektif karena mengedepankan persamaan dan perbedaan kosa kata, sehingga pemanfaat crossword puzzle diharapkan dapat mengurangi kejenuhan siswa yang selalu dihadapkan dengan pertanyaan-pertanyaan baku saja? .

Dalam bahasa Arab, terminologi crossword puzzle dikenal dengan kata al kalimah al mutaqoti'ah. crossword puz:le ini sangat mudah dalam pembuatannya dan mudah pula bagi guru maupun siswa

\footnotetext{
6 Nandang Sarip Hidayat, "Problematika Pembelajaran Bahasa Arab,” An-Nida' 37, no. 1 (2012): 83, http://ejournal.uin-suska.ac.id/index.php/Anida/article/view/315.

${ }^{7}$ Wakhidati Nurrohmah Putri, "Pengaruh Media Pembelajaran Terhadap Motivasi Belajar Bahasa Arab Siswa Madrasah Tsanawiyah," LISANLA: Journal of Arabic Education and Literature 1, no. 1 (2017): 1, https://doi.org/10.18326/lisania.v1i1.1160.

${ }^{8}$ Nana Sudjana dan Ahmad Rivai, Media Pembelajaran (Bandung: Sinar Baru Algensindo, 2007).

9 Nia Hidayati, "Manfaat Teka Teki Silang Sebagai Penambah Wawasan Dan Mengasah Kemampuan," niahidayati.net, 2010.
} 
untuk menggunakannya, baik tingkat pemula, menengah sampai tingkat lanjutan. Namun, hal yang harus diperhatikan saat akan menggunakan crossword puzzle sebagai media pembelajaran ialah bahwa media tersebut harus sejalan dengan materi yang akan diajarkan. Khailullah menyebutkan pertanyaan-pertanyaan yang dimuat dalam crossword puгzle harus bersumber dari materi yang dipelajari untuk mempermudah ketercapaian tujuan pembelajaran maharah qira'ah ${ }^{10}$.

Kemajuan teknologi saat ini menjadikan daya pikir siswa meningkat dan kreatif, melahirkan hal-hal baru dalam pembelajaran dan mampu mencari sumber belajar sendiri. hal ini menuntut guru untuk lebih memperkaya pengetahuan dan keterampilan dalam menyampaikan materi pembelajaran. Membelajarkan mahrah qira'ah dalam kelas tidak terlalu membutuhkan media yang muluk-muluk sehingga memberatkan guru untuk mendapatkannya. Tujuan penggunaan media crossword puzzle adalah guru menjadi terbantu dalam menyampaikan materi ajar kepada siswa ${ }^{11}$.

Penggunaan crossword puzzle dalam pembelajaran maharah qira'ah memaksa siswa untuk berpikir kritis (critical thingking) dan mendalam agar bisa menemukan jawaban yang tepat dalam mengisi kotak-kotak kosong yang terdapat dalalm crossword puzzle. Penggunaan crossword puгzle sebagai media pembelajaran maharah qira'ah sebagai tanda bahwa belajar bahasa Arab bukan aktivitas kaku, monoton dan hanya bisa mengandalkan buku paket. Tetapi belajar bahasa Arab sangat menyenangkan dan praktis karena pengajarannya bisa dilakukan dengan media-media sederhana dan mudah didapat serta menyenangkan saat menjalankan media tersebut ${ }^{12}$.

Agar media yang digunakan membantu guru dalam mencapai tujuan pembelajaran, mesti dilakukan dengan cara yang tepat saat menggunakannya. Berikut adalah langkah-langkah yang ditempuh saat menggunakan crossword puzzle dalam pembelajaran maharah qira'ah yaitu : (a) Guru memperkenalkan crossword puzzle terlebih dahulu kepada siswa di depan kelas (bagi tingkat pemula) dan memperlihatkan media crossword puzzle kepada seluruh siswa (b) Guru menyusun soal-soal dalam crossword puzzle sesuai dengan materi ajar yang diajarkan kepada siswa (c) Guru menyajikan teks wacana dalam bahasa Arab kepada siswa yang mana sumber soal dalam crossword puzzle adalah dari teks wacana tersebut. Sehingga siswa dianjurkan untuk membaca teks sebelum mengisi crossword puzzle (d) Setelah memberikan contoh cara menjawab soal yang terdapat dalam crossword puzzle (e) Untuk jawaban siswa dalam kotak kosong crossword puzzle bisa dengan tulisan latin karena yang dituntut adalah keterampilan membaca teks Arab siswa sebelum menjawab soal crossword puгzle (f) Agar lebih terampil, guru mempersiapkan lembar crossword puzzle di dalam kertas selembar. Hal ini mempermudah siswa untuk mengerjakan soal tersebut. Bila ingin lebih

${ }^{10}$ M. Khailullah, Media Pembelajaran Babasa Arab (Yogyakarta: Aswaja Pressindo, 2014).

11 S.Ag. MA M. Khalilullah, "Permainan Teka-Teki Silang Sebagai Media Dalam Pembelajaran Bahasa Arab (Mufradat)," Jurnal Pemikiran Islam 37, no. 1 (2012): 15-26.

12 M. Khailullah, "Permainan Teka Teki Silang Sebagai Media Dalam Pembelajaran Bahasa Arab (Mufradat)," Jurnal Pemikiran Islam 37, no. 01 (2012): 24. 
terampil lagi, bisa dibuat dalam bentuk crossword puгzle online (g) Setelah Siswa mengerti alur dalam mengerjakan crossword puz:le ini, mereka dipersialhkan untuk melakukannya dengan mandiri. Sdangkan guru tetap memantau pekerjaan siswa di depan kelas. Sebagai antisipasi adanya pertanyaan yang muncul dari siswa saat mengerjakan crossword puzzle (h) Bila siswa telah selesai mengerjakan crossword puгzle, seluruh siswa saling tukar kertas jawaban dengan teman di sebelahnya. Guru mulai melakukan koreksi terhadap jawaban siswa yang terdapat pada kotak crossword puгzle. Kemudian guru membetulkan jawaban siswa yang salah (i) Setelah semua proses pengerjaan crossword puz:le selesai, guru memberikan kesempatan kepada siswa untuk menjelaskan isi teks wacana yang diberikan. Dari penjelasan siswa itu guru bisa mengambil kesimpulan tingkat pemahaman siswa terhadap teks wacana tersebut (j) Terakhir, guru disarankan untuk memberikan reword kepada siswa yang betul dalam mengerjakan crossword pu₹zle ini. Hal ini dilakukan untuk meningkatkan motivasi belajar siswa terdap bahasa Arab dan memacu teman-temannya yang lain untuk lebih fokus dalam mengerjakann soal-soal yang diberikan pada pertemuan berikutnya.

Maharah qira'ah merupakan salah satu keterampilan mendasar dalam mempelajari bahasa Arab bagi non Arab. Karenanya seseorang mampu membaca Al-Qur'an, Hadist, kitab klasik yang ditulis berbahasa Arab dengan baik dan benar ${ }^{13}$. Salah satu dari empat keterampilan berbahasa yang harus dimiliki oleh pembelajar bahasa Arab ialah maharah qira'ah, yang saling memiliki keterkaitan yang tak bisa dipisahkan satu sama lainnya. Sehingga keterampilan berbahasa lainnya juga akan terlibat bila mempelajari salah satu keterampilan berbahasa.

Keterampilan berbahasa ragam tulis yang bersifat reseptif skill/maharah istiqbaliyah ialah maharah qira'ah dan istima'. Sebenarnya, dapat dilakukan pengembangan maharah qira'ah secara tersendiri, terpisah dari keterampilan mendengar dan berbicara. Namun, budaya literasi yang telah mumpuni dan berkembang yang dimiliki oleh masyarakat, sering kali mengembangkan maharah qira'ah secara terintegrasi dengan maharah itima' dan kalam ${ }^{14}$.

Pengembangan maharah qira'ah oleh lembaga-lembaga pendidikan dianggap perlu mendapat perhatian lebih. Seorang pembelajar sangat rentan keliru dalam memahami teks berbahasa Arab bila keterampilan membacanya rendah. Oleh karenanya Mahmud 'Ali Saman menyebutkan dalam kitabnya At-Taujih fi Tadris Al-Lughah Al-'Arabiyah salah satu tujuan pembelajaran maharah qira'ah ialah untuk menambah pemahaman tentang struktur bahasa dan meningkatkan kemampuan dalam megungkapkan makna dan pemikiran yang dibaca dengan baik dan benar ${ }^{15}$.

${ }^{13}$ Umar Shiddiq Abdullah, "Ta'lim Al-Lughah Al-Arabiyah Li An-Nathiqin Bi Ghairiha, At-Thurq-Al-AsalibAl-Wasail" (Al-Khurthum: Ad-Dar Al-'Alamiyah, 2008).

${ }^{14}$ Yeti Mulyati, "Hakikat Keterampilan Berbahasa," Pdgk4101/Modul1, 2015, 13.

15 Mahmud 'Ali Saman, At-Taujï Fi Tadris Al-Lughah Al-'Arabiyah (Al-Qahirah: Dar Al-Ma'arif, 1119). 
Pembelajaran maharah qira'ah yang diharapkan tidak hanya terbatas pada lancar dan fasihnya seseorang saat membaca teks saja, tetapi ia juga harus memahami teks bacaan yang ia baca, sehingga ia bisa memperoleh pengetahuan dari yang dibacanya melalui komunikasi secara tidak langsung dengan si penulis. Apalagi jika si pembaca itu mau mentransfernya lagi kepada orang ke tiga melalui penerjemahan. Demikian juga halnya dalam upaya memahami pembicaraan orang lain ${ }^{16}$.

Membelajarkan maharah qira'ah mesti dilakukan dengan cara yang baik lagi propesional. Salah satu cara pembelajaran yang profesional ialah proses transfer ilmu dan pengetahuan yang dilakukan oleh guru menggunakan strategi atau teknik untuk mengoperasikan sebuah metode. Oleh karena itu, dalam menyusun sistematika pembelajaran berupa rencana, langkah-langkah pembelajaran yang dilakukan serta proses evaluasi hasil belajar siswa harus berkaitan erat dengan bingkai umum yaitu metode pembelajaran ${ }^{17}$.

\section{Metode}

Penelitian ini menggunakan metode eksperimen (experimental research) yang menurut Sukmadinata merupakan pendekatan penelitian kuantitatif yang paling penuh ${ }^{18}$, dalam arti memenuhi semua persyaratan untuk menguji hubungan sebab akibat. Menurut Sugiyono penelitian kuantitaif ialah data berupa angka yang diolah menggunakan statistik menjadi acuannya ${ }^{19}$. Adapun objek penelitian ini ialah siswa kelas XII SMA Islam Sabilillah Malang Boarding School, yang terbagi menjadi 5 kelas dengan jumlah 125 siswa, dua kelas untuk putri dan tiga kelas lainnya untuk putra. Peneliti menggunakan metode purposice sampling dalam pengambilan sampel yang dijadikan data penelitian. Purposive sampling bekerja dengan mempertimbangkan objek penelitian sesuai kualifikasi yang terdapat dalam penelitian ini ${ }^{20}$.

Penentuan sampel dilakukan dengan melihat jumlah objek yang akan diteliti. 10-15 atau 20$25 \%$ dari populasi dijadikan sampel jika sampel tersebut lebih dari 100. Namun jika kurang dari 100, maka lebih baik seluruhnya dijadikan sebagai objek peneltian ${ }^{21}$. Berdasarkan pertimbangan terebut di atas, peneliti mengambil dua kelas yang berbeda (putra dan putri) sebagai sampel dalam penelitian ini, yaitu kelas eksperimen ialah kelas XII MIPA 2 berjumlah 30 siswa (putri) sedangkan kelas kontrol ialah kelas XII MIPA 1B yang berjumlah 30 siswa (putra), sehingga total sampel yang dijadikan sebagai objek penelitian berjumlah 60 siswa.

\footnotetext{
16 Dede Gozali, “Idiom Dalam Bahasa Arab,” El-Ibtikar 02, no. Nomor 01 (2013): 57.

${ }^{17}$ Bisri Mustafa Abd Hamid, Uril Bahrudin, Pembelajaran Bahasa Arab: Pendekatan, Strategi, Materi Dan Media

18 Sukmadinata, (2011)

${ }^{19}$ Sugiyono, (2011)

${ }^{20}$ Irawan Soehartono, Metode Penelitian Sosial Lainnya (Bandung: PT. Remaja Rosdakarya, 2002).

${ }^{21}$ Suharsimi Arikunto, Prosedur Penelitian Suatu Pendekatan (Jakarta: Rineka Cipta, 2006).
} (Malang, 2008). 


\section{Hasil dan Pembahasan}

\section{Pra Eksperimential}

Berdasarkan observasi yang dilakukan peneliti, peneliti melihat dalam proses pembelajaran maharah qira'ah di kelas XII SMA Islam Sabilillah Malang Boarding School menggunakan crossword puzqle, guru membagikan sebuah teks qira'ah yang disusun berdasarkan materi yang diajarkan. Materi tersebut berisi tentang "ta'aruf, 'amaliyatuna fil madrasah, al-marafiqul 'ammah, al-mihnah, aljami'ah al-marjuah wa al-usrah". Dari pengamatan peneliti, guru menyusun teks qira'ah tersebut dengan menggunakan bahasa Arab dilengkapi dengan terjemahannya. Apri (2019) mengatakan terjemahan itu dibuat untuk mempermudah siswa dalam mengisi crossword pu₹zle. Sedangkan media crossword puzzle sendiri dibuat secara manual menggunakan crossword puzzle maker sebanyak 25 soal mendatar dan 25 soal menurun. Setelah kotak-kotak tersebut selesai lalu kemudian di convert ke microsoft word office. Di bawah ini merupakan gambar kotak crossword puгzle, teks qira'ah dan soalsoalnya :

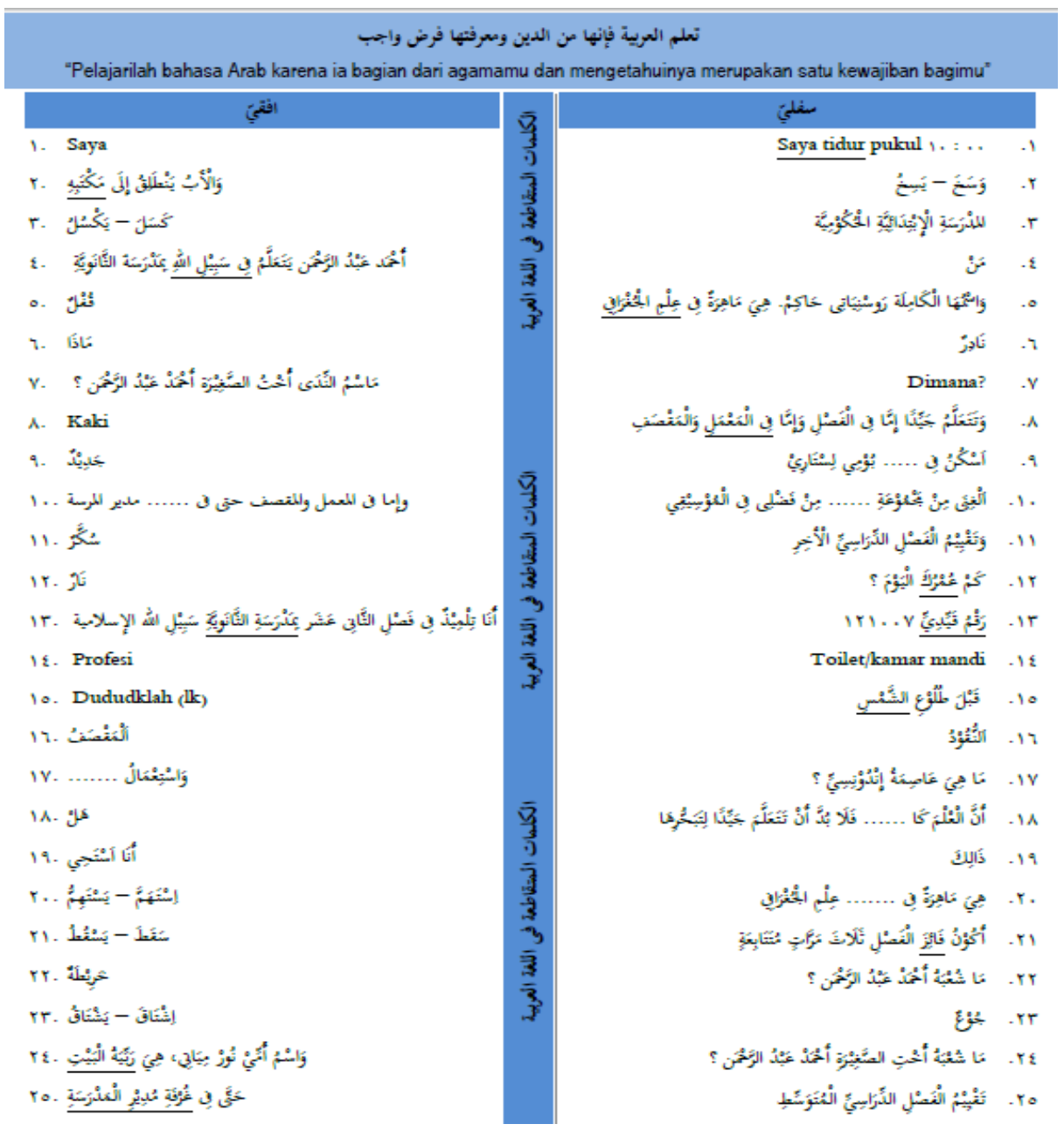

Gambar 1 : Teks qira'ah crossword puzzle 


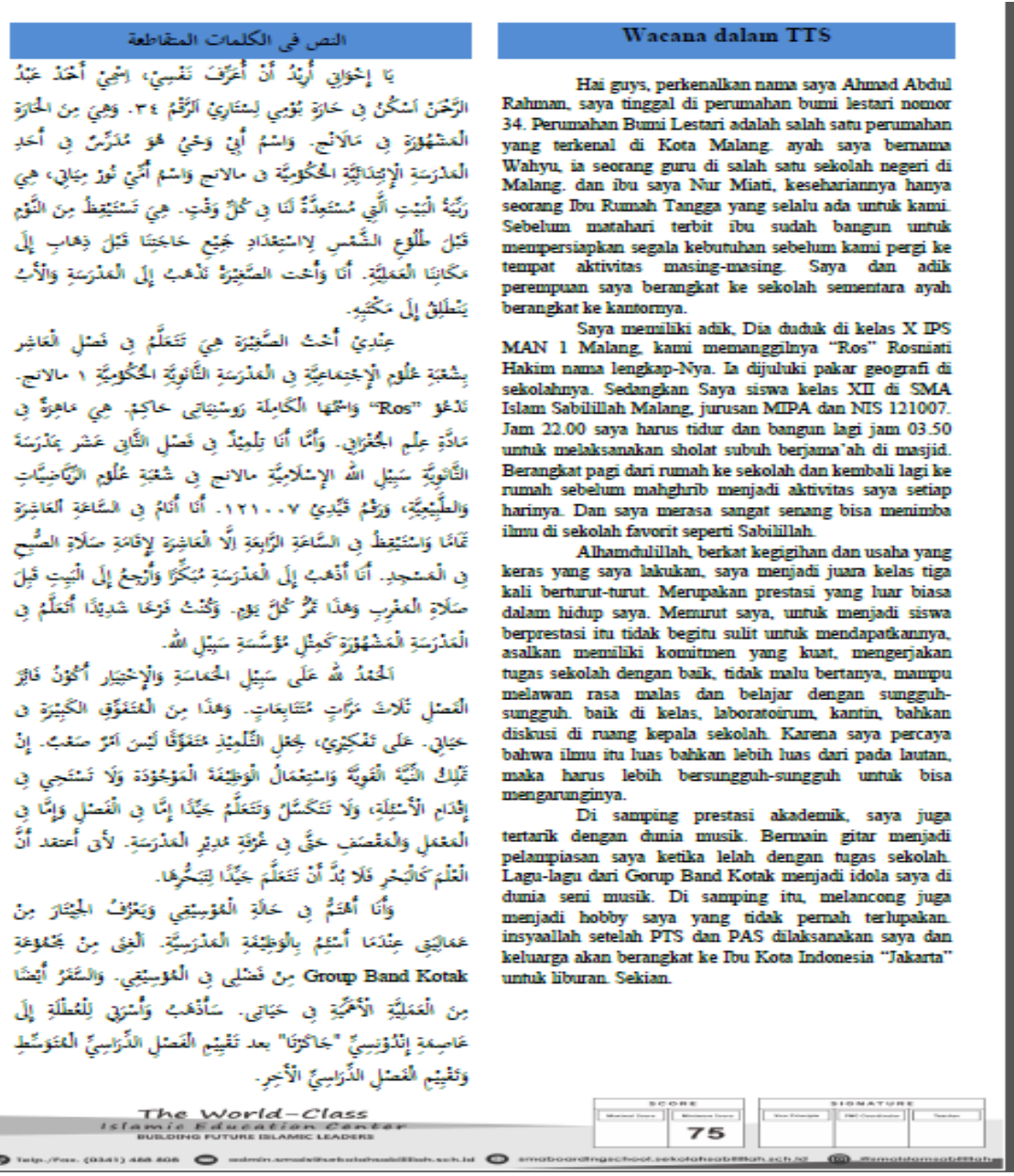

Gambar 2 : Butir-butir soal crossword puzzle

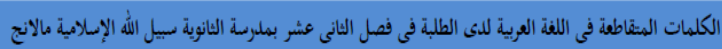

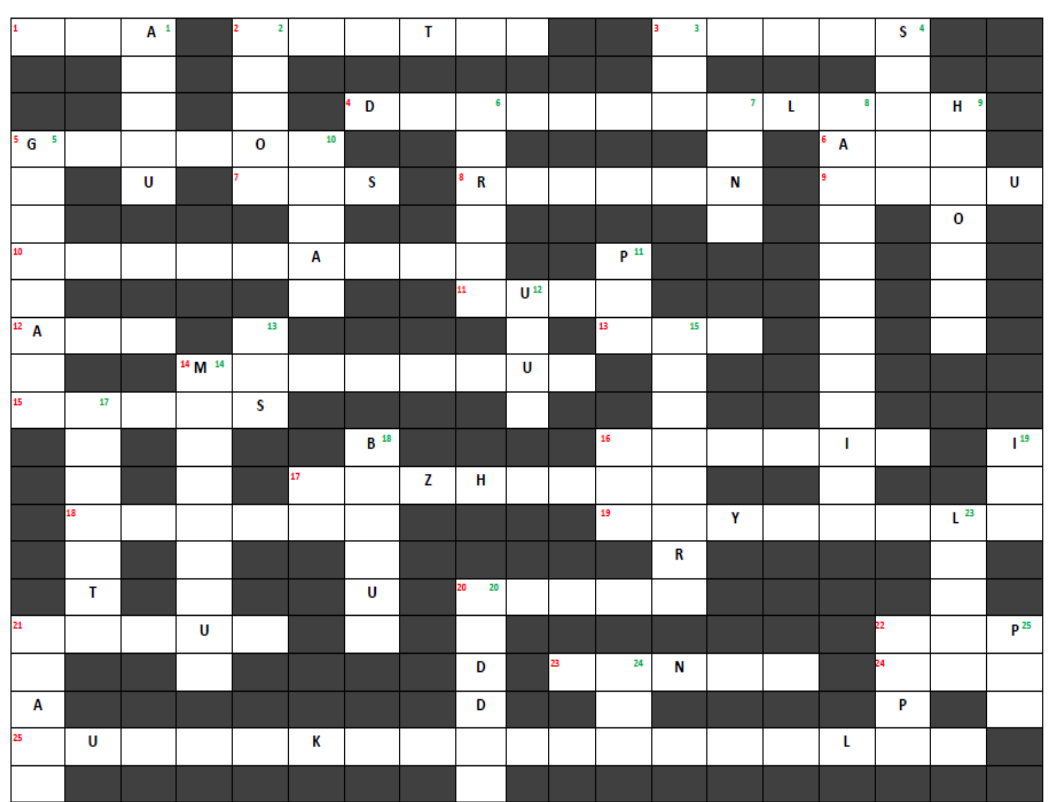

Gambar 3 : Kotak crossword puг‡le 
Sebagai langkah awal dalam penelitian ini, peneliti membagikan soal-soal pre-test sebelum menggunakan media crossword pu₹zle untuk mengetahui keterampilan qira'ah siswa sebelum menggunakan media crossword puzqle. Sedangkan untuk mengetahui pengaruh penggunaan crossword puгzle dalam pembelajaran maharah qira'ah, peneliti membagikan soal-soal post-test setelah menggunakan crossword puzzle sebagai media pembelajaran. Selanjutnya peneliti melakukan olah data menggunakan statistik untuk mengetahui tingkat signifikansi pengaruh media crossword puz:le dalam meningkatkan maharah qira'ah kelas XII SMA Islam Sabilillah Malang Boarding School.

\section{Analisi Data Tes Pembelajaran Maharah Qira'ah Menggunakan Crossword Puzzle}

a. deskripsi data dan analisis pre-test

Berikut ini adalah nilai pre-test kelas eksperimen dan kontrol :

Kelas Eksperimen:

\begin{tabular}{|c|c|c|}
\hline No & $\begin{array}{c}\text { Responden } \\
\text { (R) }\end{array}$ & $\begin{array}{c}\text { Nilai Pre-test } \\
\text { (X) }\end{array}$ \\
\hline 1 & 1 & 76 \\
\hline 2 & 2 & 68 \\
\hline 3 & 3 & 75 \\
\hline 4 & 4 & 68 \\
\hline 5 & 5 & 79 \\
\hline 6 & 6 & 78 \\
\hline 7 & 7 & 70 \\
\hline 8 & 8 & 87 \\
\hline 9 & 9 & 86 \\
\hline 10 & 10 & 78 \\
\hline 11 & 11 & 70 \\
\hline 12 & 12 & 89 \\
\hline 13 & 13 & 90 \\
\hline 14 & 14 & 97 \\
\hline 15 & 15 & 76 \\
\hline 16 & 16 & 75 \\
\hline 17 & 17 & 80 \\
\hline 18 & 18 & 69 \\
\hline 19 & 19 & 78 \\
\hline 20 & 20 & 79 \\
\hline 21 & 21 & 84 \\
\hline
\end{tabular}

Kelas Kontrol:

\begin{tabular}{|c|c|c|}
\hline No & $\begin{array}{c}\text { Responden } \\
\text { (R) }\end{array}$ & Nilai Pre-test $(\mathrm{X})$ \\
\hline 1 & 1 & 87 \\
\hline 2 & 2 & 89 \\
\hline 3 & 3 & 89 \\
\hline 4 & 4 & 86 \\
\hline 5 & 5 & 87 \\
\hline 6 & 6 & 67 \\
\hline 7 & 7 & 78 \\
\hline 8 & 8 & 80 \\
\hline 9 & 9 & 86 \\
\hline 10 & 10 & 93 \\
\hline 11 & 11 & 89 \\
\hline 12 & 12 & 87 \\
\hline 13 & 13 & 88 \\
\hline 14 & 14 & 78 \\
\hline 15 & 15 & 86 \\
\hline 16 & 16 & 90 \\
\hline 17 & 17 & 70 \\
\hline 18 & 18 & 89 \\
\hline 19 & 19 & 70 \\
\hline 20 & 20 & 79 \\
\hline 21 & 21 & 95 \\
\hline
\end{tabular}


82 | Volume 11, Nomor 2, Desember 2020

\begin{tabular}{lll}
\hline 22 & 22 & 83 \\
\hline 23 & 23 & 84 \\
\hline 24 & 24 & 85 \\
\hline 25 & 25 & 86 \\
\hline 26 & 26 & 86 \\
\hline 27 & 27 & 85 \\
\hline 28 & 28 & 84 \\
\hline 29 & 29 & 80 \\
\hline 30 & 30 & 70 \\
\hline & Jumlah & $\mathbf{2 3 9 5}$ \\
\hline
\end{tabular}

Rata-rata $: \gamma=\frac{\sum y}{n}=\frac{2395}{30}=80$

\begin{tabular}{lll}
\hline 22 & 22 & 79 \\
\hline 23 & 23 & 87 \\
\hline 24 & 24 & 89 \\
\hline 25 & 25 & 93 \\
\hline 26 & 26 & 80 \\
\hline 27 & 27 & 89 \\
\hline 28 & 28 & 80 \\
\hline 29 & 29 & 79 \\
\hline 30 & 30 & 80 \\
\hline & Jumlah & $\mathbf{2 5 1 9}$
\end{tabular}

Rata-rata $: \gamma=\frac{\sum y}{n}=\frac{2519}{30}=84$

Berdasarkan tabel di atas, perolehan nilai kelas kontrol dan eksperimen pada saat pre-test jika diurutkan berdasarkan kelompok interval pada kelas eksperimen maka pemerolehan nilai 10091 sebanyak satu orang, perolehan nilai 90-81 sebanyak dua belas orang, perolehan nilai 80-71 sebanyak sebelas orang, perolehan nilai 70-61 sebanyak tiga orang, perolehan nilai 50-41 sebanyak tiga orang. Sementara kelas kontrol nilai tertinggi adalah 95 dan nilai terendah 67. Dapat dilihat bahwa nilai rata-rata kelas eksperimen adalah 79,83 digenapkan 80 sementara kelas kontrol 83,96 digenapkan 84 .

b. deskripsi data analisis post-test

Berikut ini adalah nilai pos-test kelas eksperimen dan kontrol :

Kelas Eksperimen:

Kelas Kontrol:

\begin{tabular}{ccc}
\hline No & $\begin{array}{c}\text { Responden } \\
(\mathrm{R})\end{array}$ & $\begin{array}{c}\text { Nilai Post-test } \\
(\mathrm{X})\end{array}$ \\
\hline 1 & 1 & 90 \\
\hline 2 & 2 & 90 \\
\hline 3 & 3 & 89 \\
\hline 4 & 4 & 89 \\
\hline 5 & 5 & 90 \\
\hline 6 & 6 & 90 \\
\hline 7 & 7 & 89 \\
\hline 8 & 8 & 87 \\
\hline 9 & 9 & 89 \\
\hline 10 & 10 & 80 \\
\hline 11 & 11 & 70 \\
\hline 12 & 12 & 79 \\
\hline
\end{tabular}

\begin{tabular}{ccc}
\hline No & Responden (R) & $\begin{array}{c}\text { Nilai Post-test } \\
(\mathrm{X})\end{array}$ \\
\hline 1 & 1 & 80 \\
\hline 2 & 2 & 87 \\
\hline 3 & 3 & 88 \\
\hline 4 & 4 & 78 \\
\hline 5 & 5 & 87 \\
\hline 6 & 6 & 67 \\
\hline 7 & 7 & 78 \\
\hline 8 & 8 & 80 \\
\hline 9 & 9 & 86 \\
\hline 10 & 10 & 90 \\
\hline 11 & 11 & 89 \\
\hline 12 & 12 & 87 \\
\hline
\end{tabular}




\begin{tabular}{lcc}
\hline 13 & 13 & 87 \\
\hline 14 & 14 & 88 \\
\hline 15 & 15 & 89 \\
\hline 16 & 16 & 91 \\
\hline 17 & 17 & 87 \\
\hline 18 & 18 & 78 \\
\hline 19 & 19 & 78 \\
\hline 20 & 20 & 87 \\
\hline 21 & 21 & 88 \\
\hline 22 & 22 & 76 \\
\hline 23 & 23 & 78 \\
\hline 24 & 24 & 88 \\
\hline 25 & 25 & 87 \\
\hline 26 & 26 & 93 \\
\hline 27 & 27 & 90 \\
\hline 28 & 28 & 79 \\
\hline 29 & 29 & 87 \\
\hline 30 & 30 & $\mathbf{2 5 6 3}$ \\
\hline \multicolumn{3}{c}{ Jumlah } \\
\hline Rata-rata $\boldsymbol{\gamma}=\frac{\sum \boldsymbol{y}}{\boldsymbol{n}}=\frac{\mathbf{2 5 6 3}}{\mathbf{3 0}}=\mathbf{8 5}$ \\
\hline
\end{tabular}

\begin{tabular}{llc}
\hline 13 & 13 & 88 \\
\hline 14 & 14 & 78 \\
\hline 15 & 15 & 86 \\
\hline 16 & 16 & 88 \\
\hline 17 & 17 & 70 \\
\hline 18 & 18 & 80 \\
\hline 19 & 19 & 70 \\
\hline 20 & 20 & 79 \\
\hline 21 & 21 & 80 \\
\hline 22 & 22 & 79 \\
\hline 23 & 23 & 87 \\
\hline 24 & 24 & 89 \\
\hline 25 & 25 & 87 \\
\hline 26 & 26 & 80 \\
\hline 27 & 27 & 89 \\
\hline 28 & 28 & 80 \\
\hline 29 & 29 & 79 \\
\hline 30 & 30 & 80 \\
\hline \multicolumn{3}{c}{ Jumlah } \\
\hline Rata-rata $\boldsymbol{\gamma}=\frac{\sum \boldsymbol{y}}{\boldsymbol{n}}=\frac{\mathbf{2 4 6 6}}{\mathbf{3 0}}=\mathbf{8 2}$ \\
\hline
\end{tabular}

Berdasarkan tabel di atas, perolehan nilai kelas kontrol dan eksperimen pada fase pre-test jika diurutkan berdasarkan kelompok interval pada kelas eksperimen maka pemerolehan nilai 10091 sebanyak dua orang, perolehan nilai 90-81 sebanyak sembilan belas orang, perolehan nilai 80-71 sebanyak delapan orang, perolehan nilai 70-61 sebanyak satu orang. Sementara kelas kontrol nilai tertinggi adalah 90 dan nilai terendah 67. Adapaun nilai rata-rata kelas eksperimen adalah 85,43 digenapkan 85 sedangkan kelas kontrol menurun menjadi 82,2 digenapkan 82.

\section{Analisis Hasil Perhitungan Data Pre-test dan Data Post-test}

Setelah mendapatkan data hasil pre-test dan fase pos-test, selanjutnya peneliti menghitung signifikansi data tersebut untuk mengetahui perbedaan antara keduanya (pre-test dan post-test) yang telah didapatkan dari hasil penelitian. Hasil dari perhitungan tersebut akan menghasilkan " $t$ hitung" yang akan dibandingkan dengan "t-tabel".

Penelitian menggunakan data statistik untuk menguji hipotesis penggunaan media crossword puгzle dalam pembelajaran maharah qira'ah terhadap peserta didik kelas XII SMA Islam Sabilillah Malang Boarding School. Peniliti juga melakukan analisis data untuk menjelaskan besarnya korelasi/ hubungan variabel penggunaan media crossword puzzle $(\mathrm{X})$ terhadap variabel maharah qira'ah peserta didik (Y). Maka perbandingan nilai pre-tes kelas eksperimen pembelajaran dengan menggunakan media crossword puz:le diperoleh korelasi $0,400=$ terdapat hubungan positif antara 
dua variabel tersebut. Tingkat signifikansi hubungan 0,002 itu berarti tidak terlalu signifikan. Dan untuk nilai thitung 91,539, artinya $\mathrm{t}_{\text {hitung }}>\mathrm{t}_{\text {tabel }}$ 2,001, maka Ho ditolak dan Ha diterima, artinya terdapat pengaruh pembelajaran maharah qira'ah dengan menggunakan media crossword puzzle.

Berbeda halnya dengan kelas kontrol yang mengalami penurunan nilai pembelajaran. Dari hasil analisis data pre-tes dan pos-tes yang dilakukan, dapat dilihat bahwa nilai korelasi -,269 artinya terjadi penurunan dan tidak adanya hubungan antara dua variabel. Tingkat signifikansi yang diperoleh adalah 0,038 dan nilai probabilitas uji T Paired 0,000 artinya tidak ada perbedaan antara sebelum dan sesudah pembelajaran dilakukan. sebab nilai $\mathrm{p}$ value $>0,05$.

Dalam pembelajaran maharah qira'ah berlangsung, peneliti melihat adanya faktor pendukung dan penghambat pembelajaran maharah qira'ah dengan menggunakan media crossword puzzle. Faktor-faktor tersebut dapat dilihat dalam paparan di bawah ini :

1. Faktor Pendukung

1) Dukungan pihak sekolah, baik guru waka kurikulum dan kepala sekola dalam memfasilitasi pembelajaran bahasa Arab

2) Kreativitas guru bahasa Arab dalam menyusun teks qira'ah dan media crossword puzzle

3) Crossword puzzle sudah akrab di kalangan siswa

4) Fasilitas belajar yang lengkap mendukung penggunaan crossword puzzle

5) Antusias siswa dalam mengisi crossword puzzle yang sudah diberikan oleh guru

2. Faktor Penghambat

1) Jam pembelajaran bahasa Arab hanya 30 menit (-1 JP). Bukan waktu ideal untuk mengajarkan bahasa Arab bagi siswa kelas XII, yang seharusnya 90 menit (2 JP). Hal ini membuat fokus guru dan siswa terpecah dengan mata pelajaran sesudahnya.

2) Siswa masih kesulitan dalam membaca teks qira'ah yang dibagikan. Sehingga guru harus membacakan teks qira'ah tersebut sebelum siswa mengerjakan crossword puzzle

3) Kondisi ruangan yang panas karena masuk jam siang, membuat siswa terganggu saat pembelajaran berlangsung.

\section{Kesimpulan}

Berdasarkan olah data yang dilakukan, kesimpulan yang diperoleh dari penelitian ini adalah bahwa setelah siswa diberi perlakuan (treatment) yaitu penggunaan crossword puzzle dalam pembelajaran maharah qira'ah, terlihat ada perbedaan nilai dibanding sebelum adanya perlakuan khusus, namun tidak terlalu signifikan. Tampak jelas bahwa nilai rata-rata pre-test adalah 79,83 digenapkan menjadi 80. Sedangkan nilai rata-rata post-tes 85,43 digenapkan menjadi 85 . Sedangkan tes uji signifikansi (uji t) diperoleh data nilai "t hitung" 91,539 artinya thitung $>t_{\text {tabel }}$ 2,001 yang berarti "t hitung" lebih besar dari pada "t tabel". Dengan demikian dapat disimpulkan bahwa terdapat pengaruh 
penggunaan crossword puгzle dalam pembelajaran maharah qira'ah bagi siswa kelas XII SMA Islam Sabilillah Malang Boarding School dengan taraf signifikansi 0,2\%. Peneliti merekomendasikan untuk menindaklanjuti kajian ini dengan penggunaan media crossword puzzle online dalam pembelajaran maharah qira'ah.

\section{Daftar Pustaka}

Abd Hamid, Uril Bahrudin, Bisri Mustafa. Pembelajaran Bahasa Arab: Pendekatan, Strategi, Materi Dan Media. Malang, 2008.

Abdullah, Umar Shiddiq. “Ta'lim Al-Lughah Al-Arabiyah Li An-Nathiqin Bi Ghairiha, At-ThurqAl-Asalib-Al-Wasail.” Al-Khurthum: Ad-Dar Al-'Alamiyah, 2008.

Achsin, Amir. Media Pendidikan. Ujung Pandang: IKIP, 1986.

Arikunto, Suharsimi. Prosedur Penelitian Suatu Pendekatan. Jakarta: Rineka Cipta, 2006.

Chusna, Aliba ul. "Pembelajaran Bahasa Arab Berbasis Multimedia." Cendekia: Jurnal Kependidikan Dan Kemasyarakatan 10, no. 2 (2012): 278. https://doi.org/10.21154/cendekia.v10i2.416.

Gozali, Dede. “Idiom Dalam Bahasa Arab.” El-Ibtikar 02, no. Nomor 01 (2013): 57.

Hamalik, Oemar. Media Pendidikan. Bandung: Citra Aditya, 1989.

Hidayat, Nandang Sarip. “Problematika Pembelajaran Bahasa Arab.” An-Nida’37, no. 1 (2012): 83. http://ejournal.uin-suska.ac.id/index.php/Anida/article/view/315.

Hidayati, Nia. "Manfaat Teka Teki Silang Sebagai Penambah Wawasan Dan Mengasah Kemampuan." niahidayati.net, 2010.

Khailullah, M. Media Pembelajaran Bahasa Arab. Yogyakarta: Aswaja Pressindo, 2014. . "Permainan Teka Teki Silang Sebagai Media Dalam Pembelajaran Bahasa Arab (Mufradat)." Jurnal Pemikiran Islam 37, no. 01 (2012): 24.

M. Khalilullah, S.Ag. MA. "Permainan Teka-Teki Silang Sebagai Media Dalam Pembelajaran Bahasa Arab (Mufradat)." Jurnal Pemikiran Islam 37, no. 1 (2012): 15-26.

Mulyati, Yeti. “Hakikat Keterampilan Berbahasa.” Pdgke4101/Modul1, 2015, 13.

Putri, Wakhidati Nurrohmah. "Pengaruh Media Pembelajaran Terhadap Motivasi Belajar Bahasa Arab Siswa Madrasah Tsanawiyah." LIS ANLA: Journal of Arabic Education and Literature 1, no. 1 (2017): 1. https://doi.org/10.18326/lisania.v1i1.1160.

Rivai, Nana Sudjana dan Ahmad. Media Pembelajaran. Bandung: Sinar Baru Algensindo, 2007. Romadhon, Abdul Aziz Khoiri dan Ilham Fatkhu. "Arabic Teacher: Pembelajaran Modern Bahasa Arab Berbasis E-Learning Bagi Non-Native Speaker.” In Prosiding Konferensi Nasional Bahasa Arab III, 53:290, 2017. https://doi.org/10.1017/CBO9781107415324.004.

Rosyidi, Abdul Wahab. Media Pembelajaran Bahasa Arab. Malang: UIN Malang Press, 2009. Saman, Mahmud 'Ali. At-Taujih Fi Tadris Al-Lughah Al-'Arabiyah. Al-Qahirah: Dar Al-Ma'arif, 1119. 
86 | Volume 11, Nomor 2, Desember 2020

Soehartono, Irawan. Metode Penelitian Sosial Lainnya. Bandung: PT. Remaja Rosdakarya, 2002.

Sugiyono. Metode Penelitian Pendidikan Pendekatan Kuantitatif. Bandung: Alfabeta, 2011.

Sukmadinata, Nana Syaodih. Metode Penelitian Pendidikan. Bandung, 2011. 